\title{
Nanoporesize affects complement activation
}

\author{
Natalia Ferraz, ${ }^{1}$ Bo Nilsson, ${ }^{2}$ Jaan Hong, ${ }^{2}$ Marjam Karlsson Ott ${ }^{1}$ \\ ${ }^{1}$ Department of Physical and Analytical Chemistry, Division of Surface Biotechnology, Uppsala University, \\ Uppsala 75123, Sweden \\ ${ }^{2}$ Department of Oncology, Radiology and Clinical Immunology, Division of Clinical Immunology, \\ Uppsala University, Uppsala 75123, Sweden
}

Received 28 May 2007; revised 13 August 2007; accepted 21 September 2007

Published online 9 January 2008 in Wiley InterScience (www.interscience.wiley.com). DOI: 10.1002/jbm.a.31818

\begin{abstract}
In the present study, we have shown the vast importance of biomaterial nanotexture when evaluating inflammatory response. For the first time in an in vitro whole blood system, we have proven that a small increase in nanoporesize, specifically $180 \mathrm{~nm}$ (from 20 to $200 \mathrm{~nm}$ ), has a huge effect on the complement system. The study was done using nanoporous aluminiumoxide, a material that previously has been evaluated for potential implant use, showing good biocompatibility. This material can easily be manufactured with different pore sizes making it an excellent candidate to govern specific protein and cellular events at the tissue-material interface. We performed whole blood studies, looking at complement activation after blood contact with two pore size alumina membranes (pore diameters, 20 and $200 \mathrm{~nm}$ ). The fluid phase was analyzed for complement soluble components, C3a and sC5b-9. In addition, surface adsorbed proteins were eluted and dot
\end{abstract}

blots were performed to detect IgG, IgM, C1q, and C3. All results point to the fact that $200 \mathrm{~nm}$ pore size membranes are more complement activating. Significantly, higher values of complement soluble components were found after whole blood contact with $200 \mathrm{~nm}$ alumina and all studied proteins adsorbed more readily to this membrane than to the $20 \mathrm{~nm}$ pore size membrane. We hypothesize that the difference in complement activation between our two test materials is caused by the type and the amount of adsorbed proteins, as well as their conformation and orientation. The different protein patterns created on the two alumina membranes are most likely a consequence of the material topography. (c) 2008 Wiley Periodicals, Inc. J Biomed Mater Res 87A: 575-581, 2008

Key words: nanotopography; nanoporous alumina; complement; whole blood; protein adsorption

\section{INTRODUCTION}

It is well known that surface topography of a biomaterial affects the biocompatibility in terms of cellular response and tissue integration. Early investigations mainly focused on microtopography. The results clearly indicated that cells reacted to the different micron features, for example, by aligning in grooves and by increased adherence and proliferation in the presence of nodes or pores. ${ }^{1-4}$ Lately, scientists have realized the importance of nanotopography and discovered the similarities between nanophase materials and components of biological systems. ${ }^{5-9}$ Besides, the development of easy and

Correspondence to: M. Karlsson Ott; e-mail: marjam.ott@ ytbioteknik.uu.se

Contract grant sponsor: National Institute of Health; contract grant numbers: GM-62134, EB-003968, AI-066343-01

Contract grant sponsor: Swedish Research Council; contract grant numbers: 5647, 15244

(C) 2008 Wiley Periodicals, Inc. fast fabrication methods of nanostructured surfaces has made it possible to move forward in this field. ${ }^{7,8}$

Several review articles deal with the topic of how various cell types are influenced by different nanoscale topographies, ${ }^{3,7,8}$ for example, grooves, ridges, spikes, islands, pores, wells, and nodes. Many of these features have been shown to affect the cell response in terms of adhesion, morphology, motility, phagocytic activity, and cytokine production. There is a broad range of cells used in these studies, for example, osteoblasts, ${ }^{9,10}$ fibroblasts, ${ }^{11}$ neutrophils, ${ }^{12}$ macrophages, ${ }^{13,14}$ endothelial, ${ }^{15}$ and epithelial cells. ${ }^{16}$ The majority of this work has, however, been done using isolated systems and have therefore not considered the very first events that occur when implanting a material. Working with whole blood gives the opportunity to mimic an in vivo situation and to gain insight into the interplay between blood plasma proteins, cascade systems, and the cellular components involved in biocompatibility reactions. Activation of the complement system plays a central role in the inflammatory response; it influences 
platelet and leukocyte activation and affects the recruitment and adhesion of other inflammatory cells at the implant site. Hence, the relevance of complement activation studies when evaluating a potential implant material with a specific surface topography. The complement cascade is an effector system consisting of more than 30 soluble and membrane bound proteins. The central event is the proteolytic cleavage of $\mathrm{C} 3$ into $\mathrm{C} 3 \mathrm{~b}$ and $\mathrm{C} 3 \mathrm{a}$ which is achieved by two multisubunit enzyme complexes, the C3 convertases. These enzymes can be assembled by three different activation pathways: the classical pathway, the alternative pathway, and the mannanbinding lectin pathway. The activation pathways converge in a terminal pathway that ends up forming a membrane attack complex (MAC) which disrupts the membrane integrity of pathogens. ${ }^{17,18}$ In the absence of a biological membrane, the MAC binds to $\mathrm{S}$ protein and forms sC5b-9 which remains in the fluid phase. Complement activation also releases soluble components which are anaphylatoxins that induce a variety of cellular responses: chemotaxis, vasodilatation, cell activation, and cell adhesion. It was conventionally believed that the alternative pathway was the main mechanism involved in complement activation by artificial surfaces and that the presence of nucleophilic groups on the surfaces was of major importance. ${ }^{17}$ However, more recently, it is believed that the classical pathway is relevant and that the triggering mechanism is related to conformational changes occurring in adsorbed proteins on the material surface. ${ }^{17-20}$

In this work, we have studied how different pore sizes (in the nanometer scale) on anodized aluminium, influence the proinflammatory characteristics, specifically looking at complement activation after contact with whole blood, thus giving us the possibility of studying the "whole picture" instead of specific cells in isolated systems. This has to our knowledge never been done before. Aluminium has the advantage of easily being anodized into nanoporous alumina with different pore sizes. ${ }^{21}$ The material in question has been evaluated as a potential bone implant coating ${ }^{22}$ and as a stent coating for drug delivery. ${ }^{23}$ In both cases, anodized aluminium showed favorable tissue compatibility thus leading us to believe that it is not only suitable as a model substrate for investigating protein and cellular organization on nanoscale level, but may also be used as an implant material with a great potential for controlling the type and magnitude of cellular and molecular events at the tissue-implant interface. ${ }^{5,6}$ In the course of our experiments, special attention was therefore paid to the different proteins adsorbed on the surface of the alumina. It is well established that type, amount and conformation of surface adsorbed proteins are of extreme importance for the later events taking place at the tissue-material interface such as cell attachment and tissue integration. ${ }^{24,25}$

\section{MATERIALS AND METHODS}

Anodisc $^{\mathrm{TM}}$ alumina membranes produced by Whatman International (Maidstone, England) were used in this work. The membranes are $25 \mathrm{~mm}$ in diameter and $60 \mu \mathrm{m}$ thick, with narrow pore size distribution. This study included membranes with two pore sizes, 20 and $200 \mathrm{~nm}$ (in diameter). It should be noted that the membranes have similar surface roughness and surface chemical characteristics. ${ }^{12}$

\section{Heparin coating}

The slide chambers and the blood collection materials were heparin coated using the Corline method (Corline Systems AB, Uppsala, Sweden), following the manufacturer's recommendations.

\section{Preparation of blood}

Whole blood from 10 healthy donors was collected in heparin-coated 50-mL Falcon ${ }^{\mathbb{R}}$ tubes (Becton Dickinson, USA) containing soluble heparin (Bio Iberica, Barcelona, Spain) to give final concentrations of 0.25 and 0.5 IU hepa$\mathrm{rin} / \mathrm{mL}$.

\section{Slide chamber model}

The slide chamber previously described by Hong et al. ${ }^{26}$ was used for these experiments. The device is manufactured from polymethylacrylate (PMMA) and consists of two wells that can hold a maximum volume of $1.65 \mathrm{~mL}$ each. After heparin coating, each well was filled with $1.3 \mathrm{~mL}$ of blood $(1 \mathrm{~mL}$ of blood was also collected in eppendorf tubes containing EDTA, these 0 min samples were later used as controls). The nanoporous alumina membranes were then placed covering the wells (as "lids"), thus two circular chambers were created (see Fig. 1). The slide chambers were rotated vertically at $22 \mathrm{rpm}$ for 30 or $60 \mathrm{~min}$ in a $37^{\circ} \mathrm{C}$ water bath. After incubation, $1 \mathrm{~mL}$ of blood from each chamber was removed and mixed with EDTA- $\mathrm{K}_{3}$, giving a final concentration of $4 \mathrm{mM}$. The EDTA-treated blood samples (including the $0 \mathrm{~min}$ controls) were centrifuged at $3000 \mathrm{~g}$ for $10 \mathrm{~min}$ at $+4^{\circ} \mathrm{C}$ after which the plasma was collected and stored at $-70^{\circ} \mathrm{C}$ for further analysis.

The alumina membranes were washed with veronal buffered saline containing $0.75 \mathrm{mM} \mathrm{Ca}{ }^{+2}$ and $2.5 \mathrm{mM} \mathrm{Mg}^{+2}$ $(\mathrm{pH} 7.4)$, allowed to dry at room temperature, and finally stored at $-70^{\circ} \mathrm{C}$ for further protein elution and dot blot analysis. 


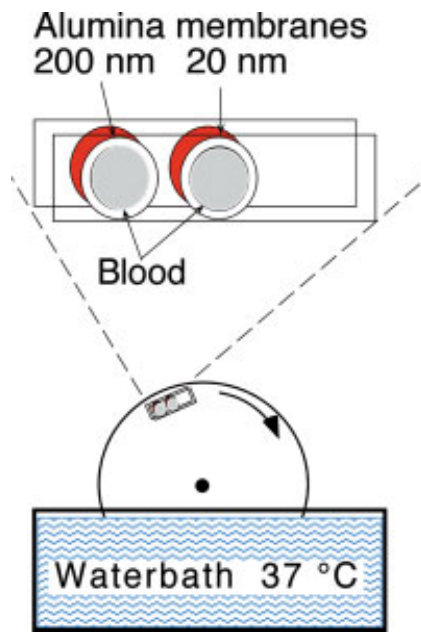

Figure 1. The slide chamber model. $1.3 \mathrm{~mL}$ of whole blood is added to each well of the slide chamber. Nanoporous alumina membranes are placed covering the wells (as "lids") thus two circular chambers are created. The slide chamber is rotated vertically at $22 \mathrm{rpm}$ for 30 or $60 \mathrm{~min}$ in a $37^{\circ} \mathrm{C}$ water bath. [Color figure can be viewed in the online issue, which is available at www.interscience.wiley. com.]

\section{Enzyme immunoassays (EIA)}

Phosphate-buffered saline (PBS) containing 1\% (w/v) bovine serum albumin (Sigma-Aldrich, St. Louis) and $0.1 \%$ TWEEN 20 (Sigma-Aldrich, St. Louis) was used as working buffer and PBS containing 0.1\% TWEEN 20 and $0.02 \%$ Antifoam $^{\mathrm{TM}}$ (Pharmacia, Uppsala, Sweden) as washing buffer.

\section{Detection of C3a}

Plasma samples diluted $1 / 1000$ or $1 / 3000$ were incubated in wells coated with monoclonal antibody 4SD17.3 (capture antibody). C3a was detected with biotinylated anti-C3a antibody (Dako, Glostrup, Denmark) followed by HRP-conjugated streptavidin (Amersham Biosciences, Little Chalfort, UK). ${ }^{27}$ Zymosan-activated serum, calibrated against a solution of purified C3a, served as a standard. Values are given in $\mathrm{ng} / \mathrm{mL}$.

\section{Detection of sC5b-9}

sC5b-9 was measured using a modification of the method described by Mollnes et al. ${ }^{27,28}$ Plasma samples were diluted $1 / 3$ or $1 / 5$ and added to microtiter plates coated with antineoC 9 monoclonal antibody. sC5b-9 was detected by polyclonal anti-C5 antibodies diluted 1/500 (Dako, Glostrup, Denmark), followed by HRP-conjugated anti-rabbit immunoglobulin diluted 1/500 (Dako, Glostrup, Denmark). Zymosan activated serum containing 40,000 $\mathrm{AU} / \mathrm{mL}$ served as standard.

\section{Protein elution and dot blot analyses}

The nanoporous alumina membranes were incubated with $2 \%$ SDS in veronal buffered saline containing $0.75 \mathrm{mM} \mathrm{Ca}{ }^{+2}$ and $2.5 \mathrm{mM} \mathrm{Mg}^{+2}$ (pH 7.4) for $3 \mathrm{~h}$ at room temperature. Three dilutions of the eluted proteins were spotted onto Immun-Blot ${ }^{\mathrm{TM}}$ PVDF membranes (BioRad Laboratories, Hercules CA) (dilutions 1/100, 1/10, and undiluted sample). The immun-blot membranes were blocked with $1 \%$ BSA in PBS containing 0.05\% TWEEN 20, and $0.02 \%$ Antifoam $^{\mathrm{TM}}$ for $30 \mathrm{~min}$. Primary antibodies against IgG, IgM, C1q (Dako, Glostrup, Denmark), and C3 (Pharmacia, Uppsala, Sweden) diluted 1/400 were used in the different dot blots performed. HRP-conjugated anti-rabbit immunoglobulin (Dako, Glostrup, Denmark) diluted 1/500 was used as secondary antibody. Antibody incubations were performed during $1 \mathrm{~h}$ at room temperature. The nitrocellulose membranes were developed using 3,3'-diaminobenzidine, tetrahydrochloride (DAB) (BioRad Laboratories, Hercules, CA) and thereafter scanned and analyzed using Imaje J. ${ }^{29}$ The intensity of the dots is expressed as integrated density (ID).

\section{Statistical analyses}

The results are expressed as mean \pm SE. Statistical significance was calculated with Student's $t$-test for unpaired samples, using Statview for Macintosh.
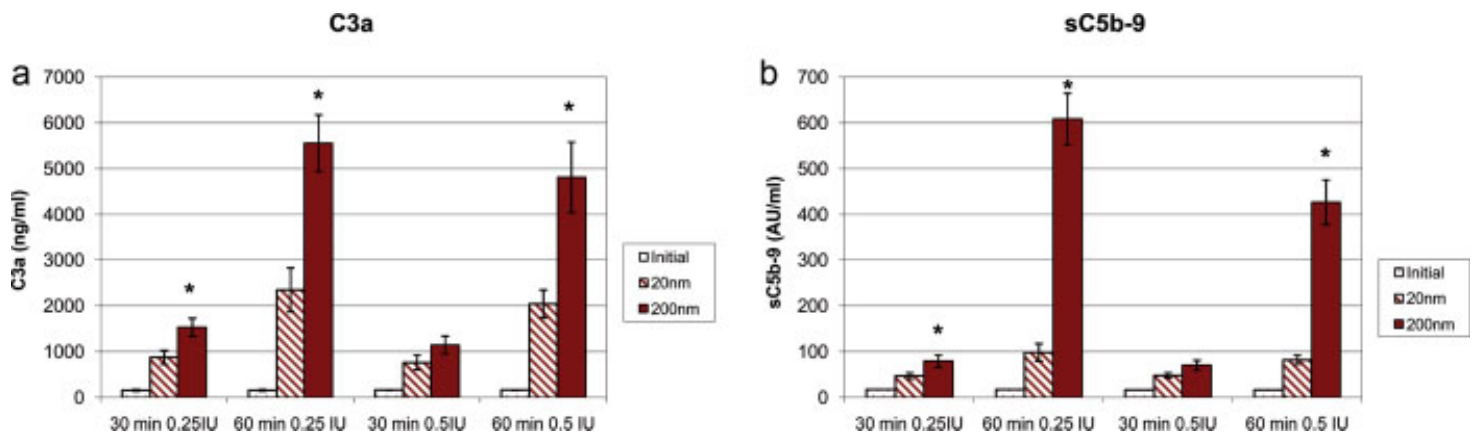

Figure 2. Complement activating properties of nanoporous alumina after whole blood contact. Experimental conditions: incubation time 30 and $60 \mathrm{~min}$, soluble heparin concentration $0.25 \mathrm{IU} / \mathrm{mL}$ and $0.5 \mathrm{IU} / \mathrm{mL}$. Comparison between 20 and $200 \mathrm{~nm}$ pore size alumina. (a) generation of C3a. (b) generation of sC5b-9. Data represent the mean \pm SE from experiments using blood from 10 different donors. Statistically significant differences between the two study materials are marked with * $(p<0.05)$. [Color figure can be viewed in the online issue, which is available at www.interscience.wiley. com.] 

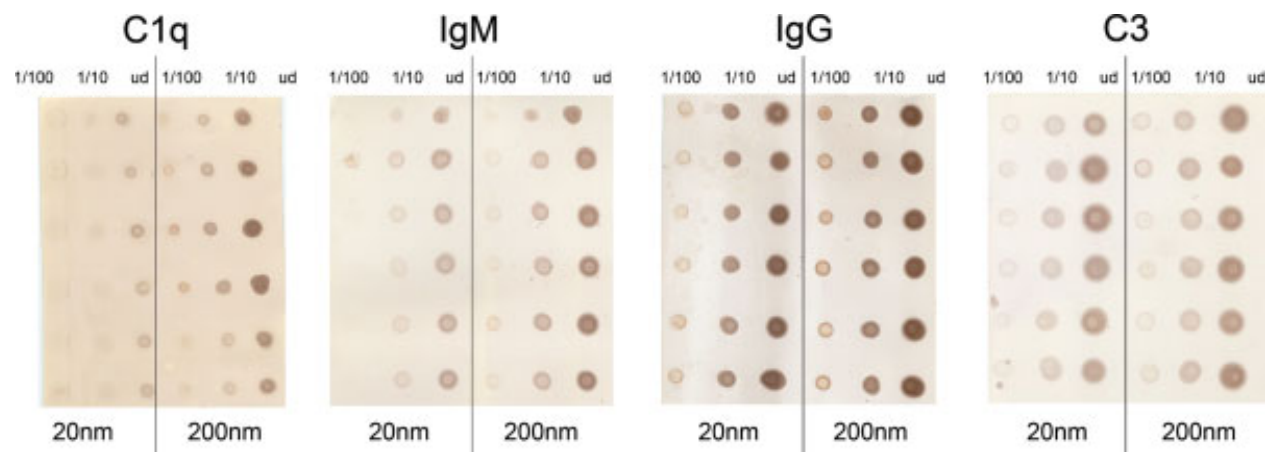

Figure 3. Dot blot membranes after color development. Each row represents a different blood donor. Experimental conditions: incubation time $60 \mathrm{~min}$, soluble heparin concentration $0.25 \mathrm{IU} / \mathrm{mL}$. Nitrocellulose membranes were scanned and analyzed using Image J; results are shown in Figure 4. [Color figure can be viewed in the online issue, which is available at www.interscience.wiley.com.]

\section{RESULTS}

\section{Generation of $\mathrm{C} 3 \mathrm{a}$ and $\mathrm{sC} 5 \mathrm{~b}-9$}

Whole blood was in contact with 20 and $200 \mathrm{~nm}$ pore size alumina for 30 and $60 \mathrm{~min}$. When comparing C3a levels generated after contact with the two alumina membranes, we found a significant difference $(p<0.05)$ after $1 \mathrm{~h}$ incubation time. Whole blood incubated with $200 \mathrm{~nm}$ membranes produced two times higher levels of the complement soluble component $\mathrm{C} 3 \mathrm{a}$, regardless of soluble heparin concentration [see Fig. 2 (a)]. After $30 \mathrm{~min}$ of incubation a similar trend was observed.

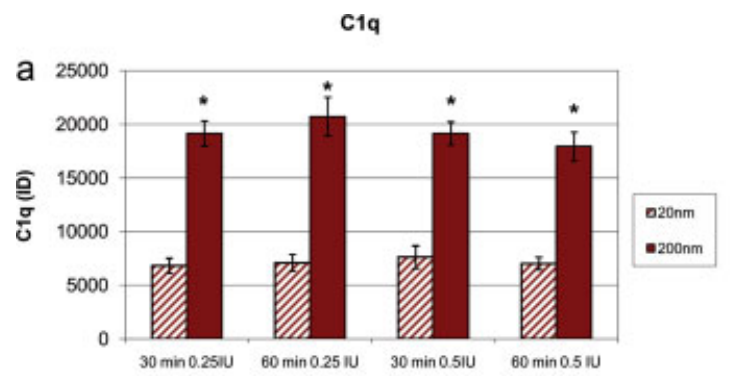

IgG

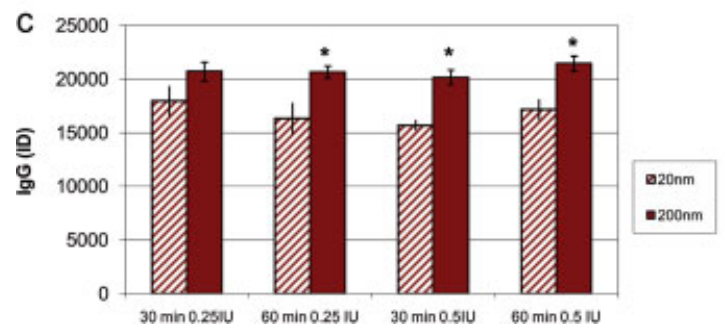

When evaluating the generation of sC5b-9, similar results to those obtained for the $\mathrm{C} 3 \mathrm{a}$ analysis were seen [see Fig. 2(b)]. In this case even higher levels (approximately five times) were detected after contact with $200 \mathrm{~nm}$ pore size membranes. The effect caused by the different pore sizes was most pronounced after $1 \mathrm{~h}$ of incubation.

\section{Analyses of bound proteins to nanoporous alumina after contact with whole blood}

The membranes were treated with $2 \%$ SDS to desorb bound proteins. The protein recovery was $75 \%$ as analyzed with BCA (Micro $\mathrm{BCA}^{\mathrm{TM}}$ Protein assay kit, Pierce). Dot blot analyses were performed
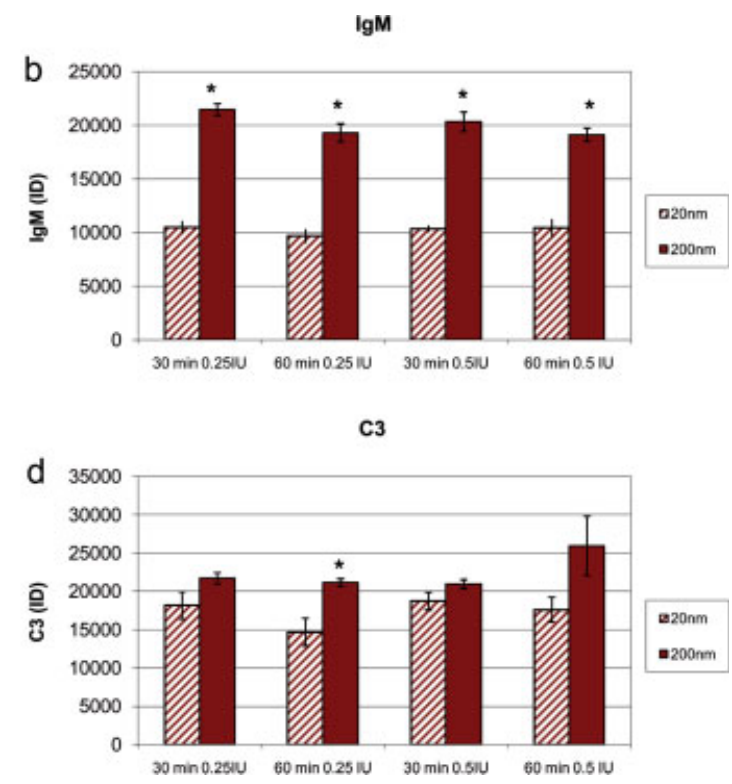

Figure 4. Dot blot analyses of bound proteins: (a) detection of C1q, (b) detection of $\operatorname{IgM}$, (c) detection of IgG, and (d) detection of C3. Data represent dot intensity expressed as integrated density (mean \pm SE). Statistically significant differences between the two study materials are marked with * $(p<0.05)$. [Color figure can be viewed in the online issue, which is available at www.interscience.wiley.com.] 
to compare the amounts of $\mathrm{C} 1 \mathrm{q}, \operatorname{IgM}, \operatorname{IgG}$, and $\mathrm{C} 3$ desorbed from the different membranes. The results show that more $\mathrm{C} 1 \mathrm{q}$, IgM, IgG, and C3 were bound to the $200 \mathrm{~nm}$ membrane than to the $20 \mathrm{~nm}$ alumina (see Figs. 3 and 4). The differences are statistically significant $(p<0.05)$ for $\mathrm{C} 1 \mathrm{q}$ and IgM regardless of incubation time or soluble heparin concentration. Similar results were obtained for IgG; however, not significant when incubated for $30 \mathrm{~min}$ with a heparin concentration of $0.25 \mathrm{IU} / \mathrm{mL}$. The $\mathrm{C} 3$ values also tend to be higher when incubated with $200 \mathrm{~nm}$ as compared to $20 \mathrm{~nm}$ alumina membranes, thus following the same pattern as for $\mathrm{C} 1 \mathrm{q}, \mathrm{IgM}$, and IgG.

\section{DISCUSSION}

The generation of activation products in blood plasma is a good indicator of complement activation; therefore, $\mathrm{C} 3 \mathrm{a}, \mathrm{C} 4 \mathrm{a}$, and $\mathrm{C} 5 \mathrm{a}$ are used as candidates to evaluate such processes. The C3a level is usually chosen as an indicator of total complement activation. C5a is the most potent anaphylatoxin but has the disadvantage of rapidly being coupled to its receptor (C5aR). Measurement of sC5b-9 is, however, an excellent way to quantify terminal complement activation and to indirectly assess C5a levels. ${ }^{20}$

In the present study, we found that both $\mathrm{C} 3 \mathrm{a}$ and sC5b-9 levels in plasma were significantly higher $(p<0.05)$ after blood contact with $200 \mathrm{~nm}$ pore size membrane as compared to the $20 \mathrm{~nm}$ membrane. Since generated C3a may bind to the biomaterial surface, $^{30,31}$ evaluation of complement activation only in the fluid phase could be misleading. Therefore, a Western blot was performed to detect bound C3a (unpublished data). Although C3a was found to bind to both alumina surfaces, the levels were higher on the $200 \mathrm{~nm}$ membrane. This leads us to conclude that complement activation is more pronounced when blood is in contact with $200 \mathrm{~nm}$ pore size alumina as reflected by the generation of higher levels of soluble components.

For blood-material interactions protein adsorption is a critical feature. Dot blot analyses were therefore performed to detect amounts of adsorbed IgG, IgM, $\mathrm{C} 3$, and $\mathrm{C} 1 \mathrm{q}$ on the different alumina membranes. The intensity of the dots was measured and the results from the two membranes were compared. We found that more protein (IgG, IgM, C3, and C1q) adsorb on the $200 \mathrm{~nm}$ pore size membrane as compared to the $20 \mathrm{~nm}$ membrane. It is believed that the initial adsorption of blood proteins to a biomaterial surface trigger the subsequent molecular and cellular responses. ${ }^{32}$ Adsorption of IgG has been shown to initiate the classical pathway ${ }^{3,34}$ and IgM has proven to be a versatile molecule that may activate the comple- ment system by different mechanisms depending on the environment. ${ }^{34}$

Tengvall et al. ${ }^{35}$ has established that C3a adsorption on hydrated aluminium occurs in a $\mathrm{C} 1 \mathrm{q}$ dependent manner after prolonged serum incubations. Andersson et al. ${ }^{36}$ also suggests that complement activation is triggered when $\mathrm{C} 3 \mathrm{~b}$ binds to adsorbed plasma proteins on a material surface. Wetterö et al. ${ }^{37}$ proposes a pronounced role of $\mathrm{C} 3$ opsonization of the material surface in complement initialization, probably occurring through multiple interactions between C3 and other rapidly adsorbed proteins. In summary, it is of major importance to evaluate the specific protein pattern created on a surface. The fact that all studied proteins (IgG, $\operatorname{IgM}$, C3, and $\mathrm{C} 1 \mathrm{q}$ ) adsorb more readily to the $200 \mathrm{~nm}$ pore size alumina than to the $20 \mathrm{~nm}$ membrane correlates well with the high levels of activation products C3a and sC5b-9 produced when whole blood has been in contact with the $200 \mathrm{~nm}$ membrane. In conclusion, all studies point to the fact that an increase of $180 \mathrm{~nm}$ in pore size leads to a significant increase in complement activation. This increased activation might lead to assembly of inflammatory cells which in turn can lead to a chronic inflammation or impair the host defense to subsequent infections thus causing implant failure. Wetterö et al. has in fact shown that adsorbed $\operatorname{IgG}$ on a biomaterial and the associated complement activation, also amplifies the neutrophil inflammatory response. ${ }^{38}$ We therefore hypothesize that if used as a blood contacting implant device a smaller surface porosity (around $20 \mathrm{~nm}$ in diameter) is favorable.

As established by Karlsson et al. ${ }^{22}$ no difference in surface chemistry or topography between the membranes can be seen. It should, however, be noted that inside the membranes (on the inner surface of the pore walls) traces of the stable anion species $\left(\mathrm{PO}_{4}^{3-}\right)$ from the electrolyte used $\left(\mathrm{H}_{3} \mathrm{PO}_{4}\right)$ when manufacturing the membranes can be detected. The phosphate group $\left(\mathrm{PO}_{4}^{3-}\right)$ could in turn affect the binding of certain proteins especially smaller proteins that are able to diffuse into the pores.

Studies conducted by Sutherland et al. ${ }^{39}$ and Denis et al. ${ }^{40}$ show that nanoscale topography can alter functional behavior of certain proteins. Sutherland et al. speculates that fibrinogen molecules adopt different orientation or conformation on structured surfaces as compared to that of a flat surface thus making specific binding sites accessible to receptors in the platelet membrane. ${ }^{39}$ Since the pores on our test materials are in the same size range, it is very likely that the same reasoning can be applied on our study, that is, the difference in complement activation between our two test materials is caused by the type and the amount of adsorbed proteins as well as their conformation and orientation. The smaller pro- 
teins, for example, IgG and C3 might easily diffuse into and bind to the internal surface of the $20 \mathrm{~nm}$ membrane while larger proteins such as $\operatorname{IgM}$ and C1q should mainly bind to the macroscopic surface. The different pore diameters result in a difference in accessible surface area for the proteins depending on their size and shape. Large proteins are able to diffuse into the $200 \mathrm{~nm}$ pores while they only adsorb to the macroscopic surface of the $20 \mathrm{~nm}$ membrane. Thus, the $200 \mathrm{~nm}$ membrane presents a higher accessible surface area than the $20 \mathrm{~nm}$ alumina. One can also speculate that on the $200 \mathrm{~nm}$ membrane the proteins have more freedom to adopt different conformations, thus making specific binding sites available. A combination of these two phenomena, most likely, cause the variation in complement activation. The present study demonstrates the importance of controlling the nanotexture when regulating the inflammatory response at artificial surfaces in contact with body fluids. We expect that better understanding of molecular interactions on the nanolevel will permit design strategies for controlling specific biological events.

\section{CONCLUSION}

The overall picture that emerges from the present study shows that a difference in nanopore size, specifically $180 \mathrm{~nm}$, has a huge effect on complement activation. IgG, IgM, C3, and C1q adsorb more readily to $200 \mathrm{~nm}$ pore size alumina than to the $20 \mathrm{~nm}$ membrane which also correlated well with the high levels of activation products, $\mathrm{C} 3 \mathrm{a}$ and $\mathrm{sC} 5 \mathrm{~b}-9$, produced when whole blood was in contact with the $200 \mathrm{~nm}$ alumina. This is most likely due to the different protein patterns created on the two membranes, that is, a variation in amount and type of adsorbed proteins as well as conformation and orientation which in turn would lead to a difference in availability of specific receptors and binding sites of theses proteins. Since the complement system has a central role in inflammatory response, this difference will very likely be reflected in the subsequent cellular events taking place at the site of inflammation.

With this study, we have demonstrated the importance of characterizing material topography in the nanometer range, which undoubtedly will play a significant role in biomaterial implant design.

The authors wish to thank the following people at the Department of Oncology, Radiology and Clinical Immunology, Division of Clinical Immunology, Dr Graciela Elgue and Ms Lillemor Funke for excellent technical assistance and Professor Kristina Nilsson Ekdahl for valuable discussions. Professor Jan Carlsson at the Department of Physical and Analytical Chemistry, Division of Surface Biotechnology is also acknowledged for stimulating discus- sions and brainstorming. Finally, we would like to thank all the people who kindly donated blood for the experiments.

\section{References}

1. Park JY, Gemmell CH, Davies JE. Platelet interactions with titanium: Modulation of platelet activity by surface topography. Biomaterials 2001;21:2671-2682.

2. Eriksson $\mathrm{C}$, Lausmaa J, Nygren $\mathrm{H}$. Interactions between human whole blood and modified $\mathrm{TiO}_{2}$ surfaces: Influence of surface topography and oxide thickness on leukocyte adhesion and activation. Biomaterials 2001;22:1987-1996.

3. Flemming RG, Murphy CJ, Abrams GA, Goodman SL, Nealey PF. Effects of synthetic micro and nano-structures surfaces on cell behaviour. Biomaterials 1999;20:573-588.

4. Curtis A, Wilkinson C. Topographical control of cells. Biomaterials 1997;18:1573-1583.

5. Whitesides GM. The right size in nanobiotechnology. Nat Biotechnol 2003;21:1161-1165.

6. Webster TJ, Waid MC, McKenzie JL, Price RL, Ejiofor JU. Nano-biotechnology: Carbon nanofibers as improved neural and orthopaedic implants. Nanotechnology 2004;15:48-54.

7. Curtis A, Wilkinson C. Nanotechniques and approaches in biotechnology. Trends Biotechnol 2001;19:97-101.

8. Yim EKF, Leong KW. Significance of synthetic nanostructures in dictating cellular response. Nanomed: Nanotechnol Biol Med 2005;1:10-21.

9. Webster TJ, Siegel RW, Brizios R. Osteoblast adhesion on nanophase ceramics. Biomaterials 1999;20:1221-1227.

10. Price RL, Haberstroh KM, Webster TJ. Enhanced functions of osteoblasts on nanostructured surfaces of carbon and alumina. Med Biol Eng Comput 2003;41:372-375.

11. Curtis ASG, Gadegaard N, Dalby MJ, Riehle MO, Wilkinson CDW, Aittchison. Cells react to nanoscale order and symmetry in their surroundings. IEEE Trans Nanobiosci 2004;3:6165.

12. Karlsson M, Johansson A, Tang L, Boman M. Nanoporous aluminum oxide affects neutrophil behaviour. Microsc Res Tech 2004;63:259-265.

13. Rice JM, Hunt JA, Gallagher JA, Hanarp P, Sutherland DS, Gold J. Quantitative assessment of the response of primary derived human osteoblasts and macrophages to arrange of nanotopography surfaces in a single culture model in vivo. Biomaterials 2003;24:4799-4818.

14. Wojciak-Stothard B, Curtis A, Monaghan W, Macdonald K, Wilkinson C. Guidance and activation of murine macrophages by nanometric scale topography. Exp Cell Res 1996; 223:426-435.

15. Dalby MJ, Riehle MO, Johnstone H, Affrossman S, Curtis ASG. In vitro reaction of endothelial cells to polymer demixed nanotopography. Biomaterials 2002;23:2945-2954.

16. Andersson AN, Bäckhed F, Von Euler A, Richter-Dahlfors A, Sutherland D, Kasemo B. Nanoscale features influence epithelial cell morphology and cytokine production. Biomaterials 2003;24:3427-3436.

17. Gorbet MB, Sefton MV. Biomaterial-associated thrombosis: Roles of coagulation factors, complement, platelets and leukocytes. Biomaterials 2004;25:5681-5703.

18. Nilsson B, Nilsson Ekdahl K, Mollnes TE, Lambris JD. The role of complement in biomaterial-induced inflammation. Mol Immunol 2007;44:82-94.

19. Wetterö J. Acute inflammation on model biomaterial surfaces, PhD thesis. Linköping: Linköping University; 2002.

20. Andersson J. Complement activation triggered by biomaterial surfaces, PhD thesis. Uppsala: Uppsala University; 2003.

21. Thompson GE. Porous anodic alumina: Fabrication, characterization and applications. Thin Solid Films 1997;297:192-201. 
22. Karlsson M, Pålsgård E, Wilshaw PR, Di Silvio L. Initial in vitro interaction of osteoblasts with nano-porous alumina. Biomaterials 2003;24:3039-3046.

23. Wieneke H, Dirsch O, Sawitowski t, Gu YL, Brauer $H$, Dahmen U, Fischer A, Wnendt S, Erbel R. Synergistic effects of a novel nanoporous stent coating and tacrolimus on intima proliferation in rabbits. Catheter Cardiovasc Interv 2003;60: 399-407.

24. Horbert TA. Proteins: Structures, properties and adsorption to surfaces. In: Ratner BD, Hoffman AS, Schoen FJ, Lemons JE, editors. Biomaterials Science: An Introduction to Materials in Medicine. San Diego: Academic Press; 1996. p 133-140.

25. Kasemo B, Gold J. Implant surfaces and the interface processes. Adv Dent Res 1999;13:8-20.

26. Hong J, Nilsson Ekdahl K, Reynolds H, Larsson R, Nilsson B. A new in vitro model to study interaction between whole blood and biomaterials. Studies of platelet and coagulation activation and the effect of aspirin. Biomaterials 1999;20:603-611.

27. Nilsson Ekdahl K, Nilsson B, Pekna M, Nilsson UR. Generation of iC3 at the interface between blood and gas. Scand J Immunol 1992;35:85-91.

28. Mollnes TE, Lea T, Froland SS, Harboe M. Quantification of the terminal complement complex in human plasma by an enzyme-linked immunosorbent assay based on monoclonal antibodies against a neoantigen of the complex. Scand J Immunol 1985;22:197-202.

29. Rasband WS.ImageJ. Bethesda, MD: U. S. National Institutes of Health; 1997- 2006. Available at http://rsb.info.nih.gov/ij/.

30. Gemmell C. A flow cytometric immunoassay to quantify adsorption of complement activation products (iC3b. C3d, SC5b-9) on artificial surfaces. J Biomed Mater Res 1997;37: 474-480.

31. Cheung AK, Parker CJ, Wilcox LA, Janatova J. Activation of complement by hemodialysis membranes: Polyacrylonitrile binds more C3a than cuprophan. Kidney Int 1990;37:10551059.

32. Courtney JM, Lamba NMK, Sundaram S, Forbes CD. Biomaterials for blood-contacting applications. Biomaterials 1994;15: 737-744.

33. Nilsson UR. Deposition of $\mathrm{C} 3 \mathrm{~b} / \mathrm{iC} 3 \mathrm{~b}$ leads to the concealment of antigens, immunoglobulins and bound $\mathrm{C} 1 \mathrm{q}$ in complement-activating immune complexes. Mol Immunol 2001;38: 151-160.

34. Tengvall P, Askendal A, Lundström I. Ellipsometric in vitro studies on the activation of complement by human immunoglobulins $M$ and $G$ after adsorption to methylated silicon. Colloids Surf B: Biointerfaces 2001;20:51-62.

35. Tengvall P, Askendal A, Lundström I. Studies on protein adsorption and activation of complement on hydrated aluminium surfaces in vitro. Biomaterials 1998;19:935-940.

36. Andersson J, Nilsson Ekdahl K, Lambris JD, Nilsson B. Binding of C3 fragments on top of adsorbed plasma proteins during complement activation on a model biomaterial surface. Biomaterials 2005;26:1477-1485.

37. Wetterö J, Askendal A, Bengtsson T, Tengvall P. On the binding of complement to solid artificial surfaces in vitro. Biomaterials 2002;23:981-991.

38. Wetterö J, Bengtsson T, Tengvall P. C1q-independent activation of neutrophils by immunoglobulin M-coated surfaces. J Biomed Mater Res 2001;57:550-558.

39. Sutherland DS, Broberg M, Nygren H, Kasemo B. Influence of nanosclae surface topography and chemistry on the functional behaviour of an adsorbed model macromolecule. Macromol Biosci 2001;1:270-273.

40. Denis FA, Hanarp P, Sutherland DS, Gold J, Mustin C, Rouxhet PG, Dufrene YF. Protein adsorption on model surfaces with controlled nanotopography and chemistry. Langmuir 2002;18:819-828. 